\title{
Quebec delays construction of new hospitals
}

Published at www.cmaj.ca on Jan. 19

$\mathrm{T}$ wo of the public-private partnerships under way to build hospitals in Quebec have been delayed after the province asked the private bidders to resubmit their proposals because they exceeded the original budgets.

The McGill University Health Centre (MUHC) had originally planned to announce the winner of the competition to build a \$1.1-billion expansion of the centre's Glen campus in December 2009. But the proposals bidders submitted, while technically satisfactory, did not meet the financial criteria.

"We got the bids in and they were over the budget that were specified for that project, so we sent the bidders back to the drawing board so they would [come] up with newer proposals that is closer to the agreed budget," says Hugo Delaney, communications director for L'Agence des partenariats public-privé du Québec (PPP Québec), the government agency set up to supervise public-private partnership projects for the province.

A second project - a \$320-million research centre that is part of the larger planned Montreal University Hospital Center, known as CHUM - has also been delayed after the bidders on that project also came in over budget, Delaney says.

Bidders on both projects have another 60 days to submit new financial bids, taking the new deadline into March, says Delaney.

Despite the delay, a spokesperson for the McGill University Health Centre says it still hopes to break ground on the project this spring. "Obviously, we had been very eager to announce our winner as quickly as we could," says Dianne Fagan, communications manager for the redevelopment project.

"We've been waiting for this project for a long time - more than a decade. We are very close to the end and hav-

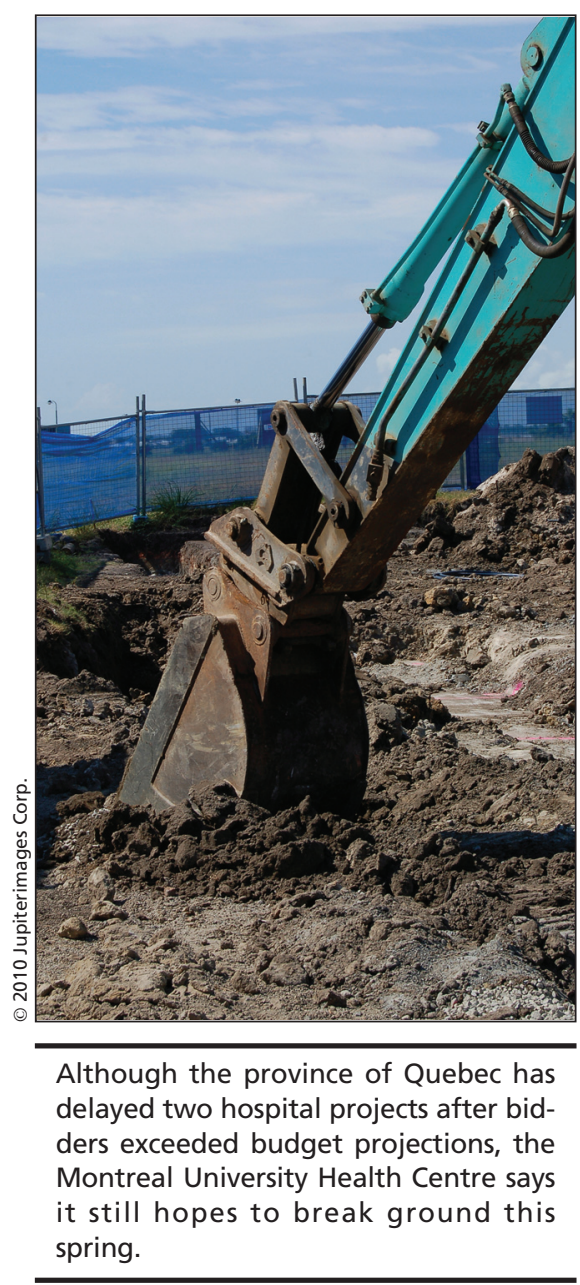

ing to do a bit more diligence at this end will be well worth it if we are moving forward in 60 days."

The two projects, in addition to the \$1.3-billion new hospital that is the centerpiece of the Université de Montréal Hospital Centre, are the first time that Quebec has financed hospital construction through the public-private partnership process (CMAJ 2008. DOI:10.1503/cmaj.081540 and CMAJ 2008. DOI:10.1503/cmaj.081633).

Originally, the province had planned to have a private consortium design, build and finance the hospitals, and subsequently own them for a period of 30 years. Quebec would pay a monthly lease to use the hospitals, topped up by a profit margin. However, that plan changed when financing became difficult, says Delaney.

"What we've agreed to do is, once construction is completed, we will give them $45 \%$ of their construction costs at that point, meaning they don't have to get long-term financing, and we will reduce the later rent payments by an equal amount."

That means Quebec taxpayers will be on the hook for an as-yet unspecified amount, because the overall \$1.1 billion price tag includes maintenance costs for the next 30 years.

"We don't know what the specific construction costs are because it's dependent on the specific proposal that wins," says Delaney.

Quebec's auditor general has warned against the public-private partnership approach, saying it will not benefit taxpayers in the long run. In a report issued by Renauld Lachance in November 2009, the auditor general said his analysis did not support PPP Québec's conclusion that a public-private partnership was preferable to the conventional method of having the government own the hospitals outright, financing them through long-term public debt.

A group of Quebec doctors, known as les Médecins québécois pour le régime public, has called on the province to abandon the public-private approach in favour of the traditional method of financing hospitals through strictly public money.

But Quebec Premier Jean Charest recently reiterated in his year-end media interviews that he is committed to the PPP process, Delaney says. Since PPP Québec was established in 2005, it has overseen bids and construction on five public-private partnership projects, including a long-term care facility on Montréal's South Shore. The other projects have included roads and a concert hall. — Laura Eggertson, Ottawa, Ont.

DOI:10.1503/cmaj.109-3159 